\title{
Informing future cartilage repair strategies: a comparative study of three different human cell types for cartilage tissue engineering
}

\author{
Sushmita Saha • Jennifer Kirkham • David Wood • \\ Stephen Curran • Xuebin B. Yang
}

Received: 25 October 2012 / Accepted: 7 February 2013 /Published online: 12 March 2013

(C) The Author(s) 2013. This article is published with open access at Springerlink.com

\begin{abstract}
A major clinical need exists for cartilage repair and regeneration. Despite many different strategies having been pursued, the identification of an optimised cell type and of pre-treatment conditions remains a challenge. This study compares the cartilage-like tissue generated by human bone marrow stromal cells (HBMSCs) and human neonatal and adult chondrocytes cultured on three-dimensional (3D) scaffolds under various conditions in vitro and in vivo with the aim of informing future cartilage repair strategies based upon tissue-engineering approaches. After 3 weeks in vitro culture, all three cell types showed cartilage-like tissue formation on 3D poly (lactide-co-glycolide) acid scaffolds only when cultured in chondrogenic medium. After 6 weeks of chondro-induction, neonatal chondrocyte constructs revealed the most cartilage-like tissue formation with a
\end{abstract}

The authors acknowledge Smith \& Nephew for their support of a PhD studentship for S.S. This work was partially funded through the NIHR Leeds Musculoskeletal Biomedical Research Unit and WELMEC, a Centre of Excellence in Medical Engineering funded by the Wellcome Trust and EPSRC, under grant number WT 088908/Z/09/Z.

S. Saha $\cdot$ D. Wood $\cdot$ X. B. Yang $(\bowtie)$

Biomaterials and Tissue Engineering Group,

Leeds Dental Institute, University of Leeds,

Leeds LS2 9LU, UK

e-mail: X.B.Yang@leeds.ac.uk

J. Kirkham

Biomineralisation Group, Leeds Dental Institute,

University of Leeds, Leeds LS2 9LU, UK

J. Kirkham $\cdot$ X. B. Yang

NIHR Leeds Musculoskeletal Biomedical

Research Unit, Leeds, UK

S. Curran

Smith \& Nephew Research Centre, York Science

Park, York YO10 5DF, UK prominent superficial zone-like layer, a middle zone-like structure and the thinnest fibrous capsule. HBMSC constructs had the thickest fibrous capsule formation. Under basal culture conditions, neonatal articular chondrocytes failed to form any tissue, whereas HBMSCs and adult chondrocytes showed thick fibrous capsule formation at 6 weeks. After in vivo implantation, all groups generated more compact tissues compared with in vitro constructs. Pre-culturing in chondrogenic media for 1 week before implantation reduced fibrous tissue formation in all cell constructs at week 3 . After 6 weeks, only the adult chondrocyte group pre-cultured in chondrogenic media was able to maintain a more chondrogenic/less fibrocartilaginous phenotype. Thus, pre-culture under chondrogenic conditions is required to maintain a long-term chondrogenic phenotype, with adult chondrocytes being a more promising cell source than HBMSCs for articular cartilage tissue engineering.

Keywords Chondrogenesis - Three-dimensional constructs · Bone marrow stromal cells $\cdot$ Neonatal chondrocytes $\cdot$ Adult chondrocytes $\cdot$ Human

$\begin{array}{ll}\text { Abbreviations } \\ \text { 2D } & \text { Two-dimensional } \\ \text { 3D } & \text { Three-dimensional } \\ \text { ACI } & \text { Autologous chondrocyte implantation } \\ \text { ALPSA } & \text { Alkaline-phosphatase-specific activity } \\ \text { CCA } & \text { Compressive cell adhesion } \\ \text { CLSM } & \text { Confocal laser scanning microscopy } \\ \text { DPX } & \text { p-Xylene bis-pyridinium bromide } \\ \text { ECM } & \text { Extracellular matrix } \\ \text { FCS } & \text { Fetal calf serum } \\ \text { FDA } & \text { Food and Drug Administration } \\ \text { HBMSCs } & \text { Human bone marrow stromal cells }\end{array}$




$\begin{array}{ll}\text { MSCs } & \text { Mesenchymal stem cells } \\ \text { NBF } & \text { Neutral buffered formaldehyde } \\ \text { PLGA } & \text { Poly (lactide-co-glycolide) acid } \\ \text { TGF- } \beta 3 & \text { Transforming growth factor beta } 3 \\ \alpha \text {-MEM } & \text { Alpha-modified minimum essential medium }\end{array}$

\section{Introduction}

Normal diarthrodial joint function requires the presence of healthy articular cartilage capable of bearing mechanical load. Damage to articular cartilage is of clinical concern because of the limited ability of the tissue to self-repair spontaneously (LeBaron and Athanasiou 2000a; Saha et al. 2011; Tuli et al. 2003). A number of clinical strategies have been adopted over the years to tackle this problem, e.g., arthroscopic lavage and debridement, periosteum and osteochondral transplantation, autologous chondrocyte implantation (ACI) and free toe and joint to hand transfer but each of these methods has its own disadvantages limiting their use (Gu et al. 1997; Redman et al. 2005; Ringe and Sittinger 2009; Tuan et al. 2003; Yang and Gu 2000). Over the last decade, cell-based therapies have shown much promise for articular cartilage regeneration; for example, Brittberg et al. (1994) have reported the successful repair of cartilage defects following autologous chondrocyte transplantation. In 1995, Genzyme employed this technique to develop "Carticel", a Food and Drug Administration (FDA)approved ACI treatment for patients with cartilage injuries of the knee. A major drawback of ACI is that it is a two-step procedure in which cells are first harvested to allow for cell expansion followed by a surgical procedure for the transplantation of the expanded cells. The adverse effects of ACI include arthrofibrosis, graft overgrowth and chondrosis (Vasiliadis et al. 2010). Other associated problems with chondrocyte transplantation are limited cell availability, loss of re-differentiation capability in vitro and a risk of donor site morbidity (Baksh et al. 2007). Moreover, no direct evidence has been presented to date to suggest that ACI treatment is superior to alternative surgical options such as microfracture or mosaicplasty. Studies comparing the cost effectiveness of ACI against that of mosaicplasty or microfracture found insufficient difference of any significance between the three procedures (Clar et al. 2005; Rodriguez-Merchan 2012; Vasiliadis et al. 2010). On the basis of these comparisons, experts have voiced the need for more basic science research into determining factors that help differentiate and maintain stem cells in a chondrogenic phenotype (Clar et al. 2005). Thus, efforts are now focused on stem cell therapy. Because of ethical issues and potential problems in the regulation of cell differentiation in vivo, the application of embryonic stem cells has been limited (Lin et al. 2005). Wei et al. (2012) have reported the use of induced pluripotent stem cells for chondrogenic differentiation. However, their reprogramming may have the risk of generating germ cell tumours (Grad et al. 2011). Adult mesenchymal stem cells (MSCs) have become a popular alternative for the treatment of cartilage injuries. MSCs are said to have extensive self-renewal, long-term cell viability and multi-lineage potential together with a lack of or minimal immunogenicity (Lin et al. 2005). Adult stem cells derived from a myriad of sources (bone marrow, fat pad, synovial fluid, dental pulp and periosteum) have demonstrated chondrogenic potential in vitro (Emans et al. 2005; Estes et al. 2006; Johnstone et al. 1998; Shintani and Hunziker 2007; Yanai et al. 2005). Some of these stem cells have been used clinically to regenerate bone but their clinical application in regenerating human cartilage is either undocumented or in the early stages (Horwitz et al. 2002; Wakitani et al. 2002). Whereas the numerous different types of adult stem cells isolated have been documented to possess the typical stem cell markers (adherence to tissue culture plastic; expression of CD105, CD73 and CD90; differentiation along chondro/osteo/adipogenic lineages), these stem cell populations have diverse proliferation rates and dissimilar differentiation potentials and respond differently to growth factors (Chen and Tuan 2008; Dominici et al. 2006). The method of cell isolation, culture, medium, growth factors, interaction with scaffold material and substrate topography are all known to affect cell proliferation and differentiation. However, different protocols are used by different research groups, making it a challenge to compare between different studies; thus, the optimum cell source and culture conditions for use in cartilage tissue repair is yet to be determined (Chen and Tuan 2008). To date, human bone marrow MSCs (HBMSCs) remain the most studied and best understood stem cell source used in cartilage tissue engineering (Chen et al. 2005; Johnstone et al. 1998; Mackay et al. 1998; Penick et al. 2005; Ponticiello et al. 2000; Wayne et al. 2005; Yanai et al. 2005)

The fabrication of ex vivo three-dimensional (3D) cartilage constructs by using functional tissue-engineering approaches has been used in an attempt to solve clinical problems of repair/regeneration of articular cartilage. The outcomes of such studies have however yielded inconsistent results (LeBaron and Athanasiou 2000a). We have previously compared HBMSCs, human adult chondrocytes and human neonatal articular chondrocytes under various twodimensional (2D) culture conditions simulating the in vitro stage of articular chondrocyte implantation therapy and have reported intrinsic differences in the microenvironment of the three cell types studied (Saha et al. 2010). In the present study, we have seeded cells on the cartilage phase of a TruFit CB (Smith \& Nephew) scaffold. This scaffold is an FDA-approved resorbable biphasic implant constituted 
predominantly from polylactide-co-glycolide copolymer (PLGA), calcium sulphate and polycolide and has a mean pore diameter of $250 \mu \mathrm{m}$ (http://www.ortovit.eu/ortopedie/ special/doc/TruFit $\% 20 \mathrm{CB} \% 20$ Plugs.pdf). The scaffold used has been documented in the literature as successfully supporting chondrocyte migration and the synthesis of chondrogenic ground matrix and has yielded promising clinical results (Agrawal and Stinson 2007; Williams and Gamradt 2008). The present study builds on our previous work and compares the genesis of 3D cartilage-like tissue in vitro and in vivo by using the same three cell types as before in an attempt to illustrate intrinsic differences between the chondrogenic potential of a progenitor cell type and immature and mature chondrocytes, which represent the three different life stages of a cartilage-forming cell and also to identify an optimum cell type for use in cartilage tissue engineering, thereby informing future cell therapy strategies for cartilage repair.

\section{Materials and methods}

Passage 1 HBMSCs (two donors aged 38 and 40 years) and primary adult chondrocytes (two donors aged 35 and 40 years) from haematologically normal donors were obtained from Lonza (UK). Primary neonatal articular chondrocytes (Passage 0) were provided by Smith \& Nephew (UK) with appropriate ethical approval and consent for use in commercial and collaborative research. Alphamodified minimum essential medium $(\alpha-\mathrm{MEM})$ and fetal calf serum (FCS) were from Lonza.

\section{Cell culture}

Cells were expanded in basal media ( $\alpha$-MEM with $10 \%$ FCS) and the medium was changed every 3 days. The cells were passaged at $70 \%-75 \%$ confluency up to a maximum of passage 4 . To induce chondrogenesis, a serum-free chondrogenic medium consisting in $\alpha$-MEM supplemented with $10 \mathrm{ng} / \mathrm{ml}$ transforming growth factor beta 3 (TGF- $\beta 3$ : Peprotech, USA), $10^{-8} \mathrm{M}$ dexamethasone, $100 \mu \mathrm{M}$ ascorbate-2-phosphate and $1 \times$ insulin transferring selenium supplement (Johnstone et al. 1998; Saha et al. 2010) was used in place of the basal medium.

\section{Dynamic seeding of cells on 3D scaffolds}

In order to visualise cell attachment and spreading on/within the scaffolds, the cells were labelled with $50 \mu \mathrm{g}$ CellTracker Green 5-chloromethylfluorescein diacetate (Invitrogen) in $5 \mathrm{ml} \alpha$-MEM for $45 \mathrm{~min}$ (Yang et al. 2006). The cells were trypsinised and $2.5 \times 10^{5}$ cells of each cell type were seeded dynamically onto the separated ultra-violet-sterilised cartilage phase of TruFit CB Plugs $\left(3 \times 1.5 \mathrm{~mm}^{3}\right)$ by using a dynamic seeding apparatus designed in house (rotational speed: $17 \mathrm{rpm}$ ) for $24 \mathrm{~h}$. Optical sections of the cell-scaffold construct (up to a depth of $300 \mu \mathrm{m}$ ) were obtained by confocal laser scanning microscopy (CLSM; Leica). Images were stacked and 3D reconstruction was carried out by using Leica confocal software enabling us to visualise cell viability up to a considerable depth within the scaffold.

In vitro static culture of cells on $3 \mathrm{D}$ scaffolds

After $24 \mathrm{~h}$ of dynamic seeding, the constructs were transferred to 24-well plates and cultured in vitro in either basal or chondrogenic medium under static conditions at $37^{\circ} \mathrm{C}$ in a humidified atmosphere of $5 \% \mathrm{CO}_{2}(n=4)$. After 3 or 6 weeks, the constructs were fixed in $10 \%$ neutral buffered formaldehyde (NBF) and embedded in paraffin. Sections ( $5 \mu \mathrm{m}$ thick) were prepared by using a Leica microtome.

In vivo intra-peritoneal implantation

All the in vivo studies were carried out under UK Home Office project license and were approved by the University of Leeds ethical committee. Briefly, cells were dynamically seeded onto scaffolds as described above. Constructs were then cultured in vitro in basal or chondrogenic media $(n=4)$ for a further 7 days and then sealed into diffusion chambers (Millipore, UK) prior to intra-peritoneal implantation in male immuno-compromised nude mice (MF1-Nu/Nu, 4 5 weeks old; Partridge et al. 2002; Yang et al. 2004). After 3 or 6 weeks, the mice were killed in compliance with UK Home Office regulations and the chambers removed and fixed in $10 \% \mathrm{NBF}$ at $4^{\circ} \mathrm{C}$. Samples were then processed in the same way as the in vitro samples.

\section{Alcian Blue/Sirius Red staining}

Alcian Blue/Sirius Red staining was used to visualise the presence of sulphated glycosaminoglycans and collagen within the constructs. Briefly, the sections were stained with Weigert's haematoxylin for $15 \mathrm{~min}$ prior to being stained with $0.5 \%$ Alcian Blue for $10 \mathrm{~min}$. After a 20 -min treatment with freshly prepared $1 \%$ molybdophosphoric acid, samples were stained for up to $1 \mathrm{~h}$ in $0.3 \%$ Sirius Red. The sections were then mounted in p-xylene bis-pyridinium bromide (DPX) and observed under an Olympus BX50 microscope by using SPOT software.

Immunohistochemical staining

Immunohistochemistry was carried out in order to assess the expression of Sox9 (rabbit polyclonal anti-SOX9; Abcam) 
and aggrecan (mouse monoclonal anti-aggrecan; Abcam) in 5 - $\mu \mathrm{m}$-thick paraffin sections of the constructs retrieved after culture in vitro and in vivo. Endogenous peroxidase activity was blocked by using $3 \%$ hydrogen peroxide and an antigen retrieval step was carried out by using an antigen unmasking vector solution (Vector Laboratories, Calif., USA). Samples were incubated in primary antibody (1/50 dilution of antiSox $9 ; 1 / 100$ dilution of anti-aggrecan) for $1 \mathrm{~h}$ at room temperature. The EnVision Kit, which contained the secondary antibody (Dako), was employed to detect peroxidase activity. All samples were processed simultaneously to ensure homogeneity in the staining procedure. Samples tested for the presence of Sox9 were counterstained in Fast Green for $30 \mathrm{~s}$. Negative controls (minus the primary antibody) were also carried out for each sample. All samples were dehydrated, cleared in xylene, mounted in DPX and observed under an Olympus BX50 microscope by using SPOT software. For any given 3D construct, consecutive paraffin sections were used to assess the expression of the different chondrogenic markers in order to minimise any depth-dependent variations that may have arisen. A qualitative assessment of the intensity of any immunostaining observed was made.

\section{Results}

Cell attachment and spreading on 3D scaffolds

After $24 \mathrm{~h}$ of dynamic seeding, CLSM 3D reconstruction images showed that the majority of cells of each cell type were viable and had attached on all sides of the scaffolds (Fig. 1). Cell morphology appeared to be stretched with elongated processes clearly visible indicating cell spreading. Cells were also observed to have penetrated into the central part of the scaffold (ingrowth). No obvious differences were noted between any of the cell types with respect to cell viability, attachment and spreading.
Alcian Blue/Sirius Red staining of in vitro 3D tissue-engineered constructs

Constructs cultured for 3 weeks in basal media in vitro revealed only limited cell proliferation and extracellular matrix (ECM) formation, confirmed by extremely faint Alcian Blue staining for all three cell types (Fig. 2a-c). In contrast, intense Alcian Blue staining (but not Sirius Red staining), together with the appearance of cells aligned parallel to the surface edge of the scaffold, was seen in the matrix of constructs following chondrogenic culture. Again, this was similar for all three cell types (Fig. 2d-f). After 6 weeks in basal medium, HBMSCs and adult chondrocyte constructs contained areas that stained intensely for Sirius Red (Fig. 2 g, i) revealing a fibrous capsule formation in the outermost layer of the constructs.However, the matrix in the neonatal articular chondrocyte constructs cultured in the same group failed to stain intensely with Alcian Blue/Sirius Red because of limited tissue formation (Fig. 2h). Under chondrogenic culture conditions, constructs for all three cell types were more cellular, with the presence of cells growing both parallel and perpendicular to the construct surfaces. A thick fibrous capsule was seen in the HBMSC constructs, which stained strongly with Sirius Red staining (Fig. 2j). In comparison, only limited Sirius Red staining was observed in adult chondrocyte constructs, with neonatal chondrocyte constructs having the thinnest fibrous capsule of all three cell types observed (Fig. 2k, 1).

Immunohistochemical analysis of $3 \mathrm{D}$ constructs cultured in vitro

Sox 9 was detected in all basal and chondro-induced constructs after both 3 weeks (Fig. 3a-f) and 6 weeks in vitro (Fig. 3g-1) with chondro-induced adult chondrocytes appearing to have visibly more Sox9-positive cells after 6 weeks in culture, although no further quantification was preformed to confirm this observation (Fig. 31). Similar
Fig. 1 Confocal images of human bone marrow stromal cells seeded onto TruFit scaffolds. The cells were labelled with live/dead fluorescent markers (green viable cells, yellow arrows attachment of viable cells onto all available areas of the 3D scaffold). Bars $94.34 \mu \mathrm{m}$ (a), $72.62 \mu \mathrm{m}(\mathbf{b})$
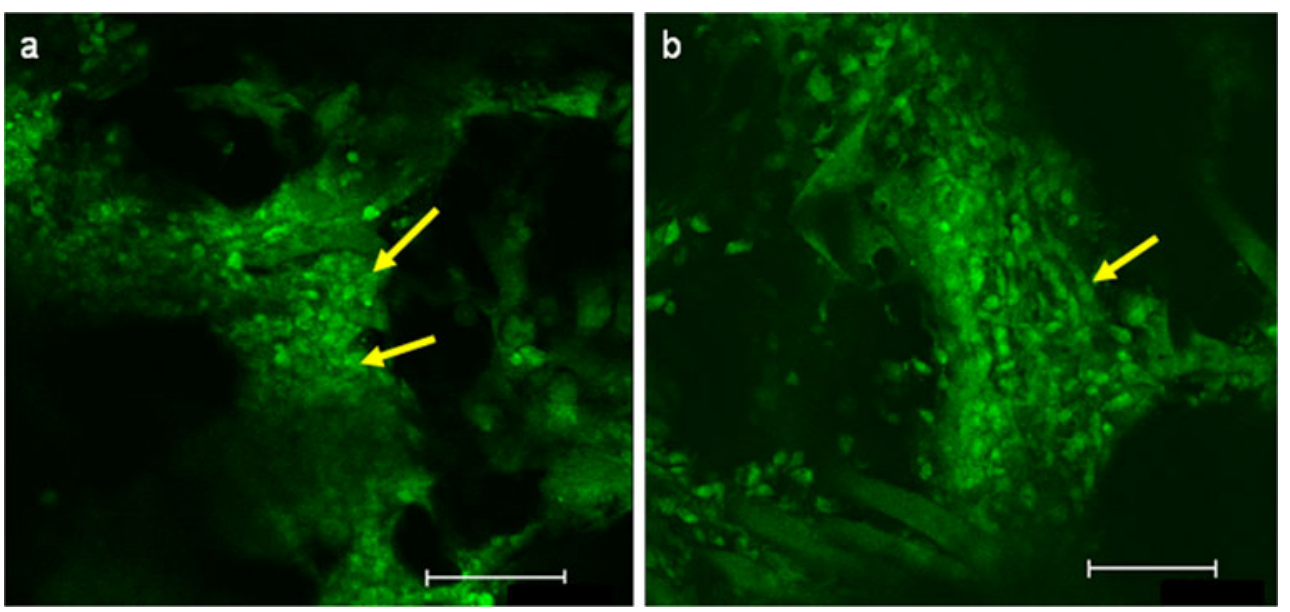
Fig. 2 Alcian Blue/Sirius Red staining of in vitro static cultured cell-scaffold constructs. Histological appearance of constructs following basal culture for 3 weeks $(\mathbf{a}-\mathbf{c})$ and 6 weeks (g-i) compared with that of chondro-inductive culture for 3 weeks $(\mathbf{d}-\mathbf{f})$ and 6 weeks $(\mathbf{j}-\mathbf{l})$. The constructs cultured in chondrogenic media at 3 and 6 weeks stain more intensely for Alcian Blue (arrows) in comparison to constructs cultured for similar time points in basal media. Constructs cultured for 6 weeks are much more cellular than those cultured for 3 weeks (red/arrowheads Sirius Red staining, $B C$ basal culture, $C C$ chondrogenic culture, $H B M S C s$ human bone marrow stromal cells). Bars $1 \mathrm{~mm}$

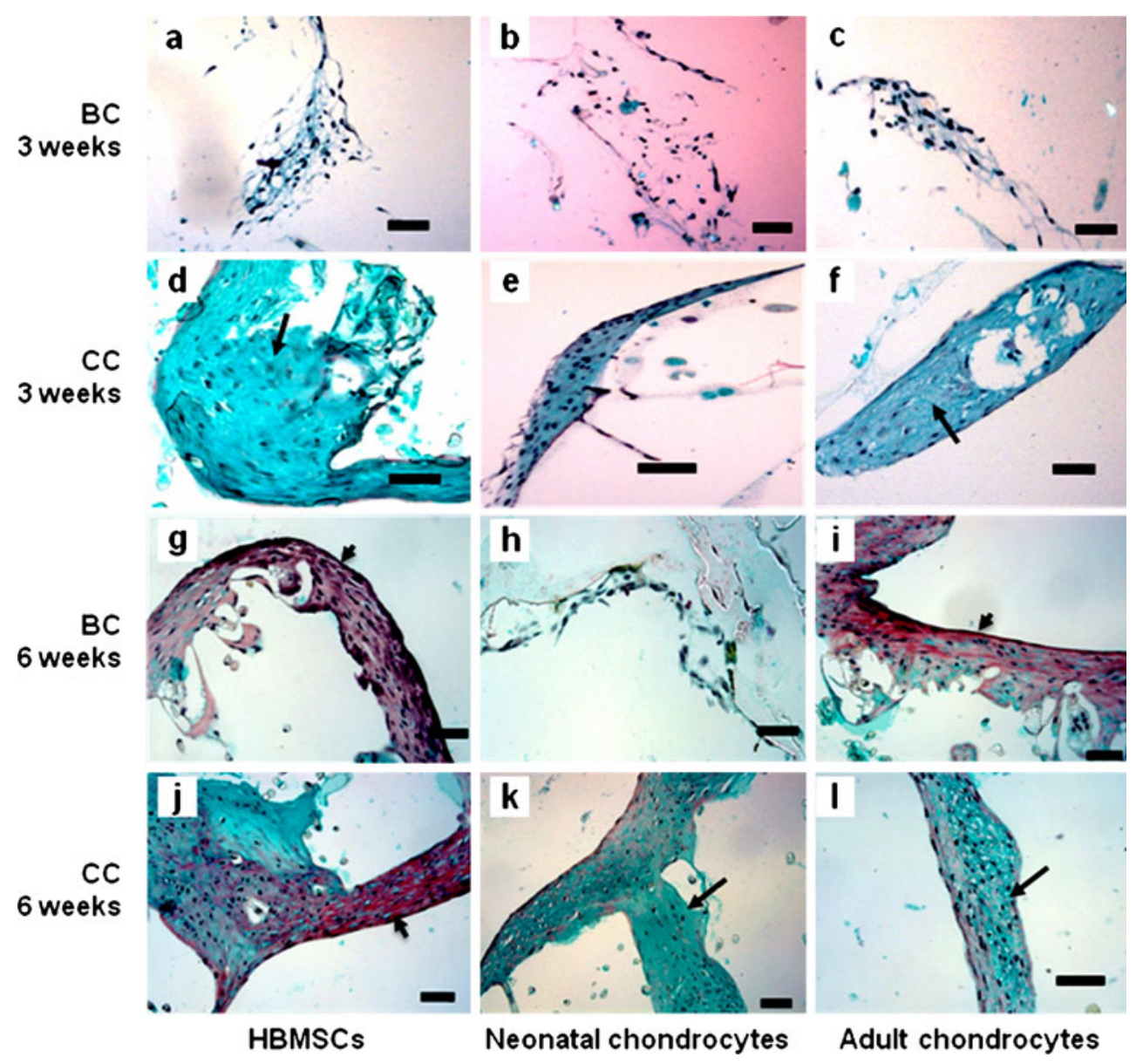

immunostaining intensities for aggrecan were detected for all three cell types cultured in either basal or chondrogenic medium for 3 weeks. After 6 weeks in basal or chondroinduced medium, all constructs appeared to have increased amounts of aggrecan as evidenced by their higher staining intensities compared to the respective 3-week constructs (Fig. 4). The highest staining intensity for aggrecan was observed at 6 weeks in the constructs containing adult chondrocytes following chondro-induction, with a similar pattern to that seen for Sox9 expression.

\section{Alcian Blue/Sirius Red staining of in vivo 3D tissue-engineered constructs}

After 3 weeks of in vivo implantation, histological examination revealed that $\mathrm{HBMSCs}$ and adult and neonatal chondrocytes formed a more compact neo-tissue (Fig. 5a-f) compared with similar constructs generated in vitro (Fig. 2a-f). However, constructs pre-cultured in basal medium for a week before implantation had a dense anionic matrix indicative of mucopolysaccharides accompanied by fibrous capsule formation (Sirius Red positive) for all cell types, with constructs containing neonatal articular chondrocytes having formed the least amount of neo-tissue
(Fig. 5a-c). In contrast, pre-chondro-induced constructs for all three cell types revealed the formation of a cartilage-like neotissue with mainly Alcian Blue staining and little Sirius Red staining at week 3 (Fig. 5d-f). After 6 weeks of in vivo implantation, HBMSC and neonatal chondrocyte constructs pre-cultured in basal medium appeared to be fragmented with a limited amount of tissue being apparent (Fig. 5g, h). Constructs containing adult chondrocytes did not appear fragmented but had copious amounts of Sirius-Red-positive staining (Fig. 51). For the constructs pre-cultured in chondrogenic medium, cartilage-like structures were seen after 6 weeks in vivo for all three cell types; however, a prominent fibrous capsule had formed in the constructs containing HBMSCs and neonatal articular chondrocytes (red staining in Fig. 5j, k). In contrast, chondro-induced adult chondrocyte constructs had little Sirius Red staining and lacked any evidence of a prominent fibrous capsule after 6 weeks of in vivo implantation (Fig. 51).

Immunohistochemical analysis of 3D constructs cultured in vivo

Sox9 was detected in both chondro-induced and nonchondro-induced constructs after 3 and 6 weeks culture in 
Fig. 3 Sox 9

immunohistochemical staining of in vitro statically cultured cell-scaffold constructs. Sox9 immunohistochemical staining of constructs following basal culture for 3 weeks $(\mathbf{a}-\mathbf{c})$ and 6 weeks (g-i) compared with that of chondro-inductive culture for 3 weeks (d-f) and 6 weeks $(\mathbf{j}-\mathbf{l})$. All sample constructs stained positively for Sox9 (arrows, dark brown) with qualitatively the highest Sox9-positive cell staining being observed for constructs cultured in chondrogenic media for 6 weeks ( $B C$ basal culture, $C C$ chondrogenic culture, HBMSCs human bone marrow stromal cells). Bars $1 \mathrm{~mm}$

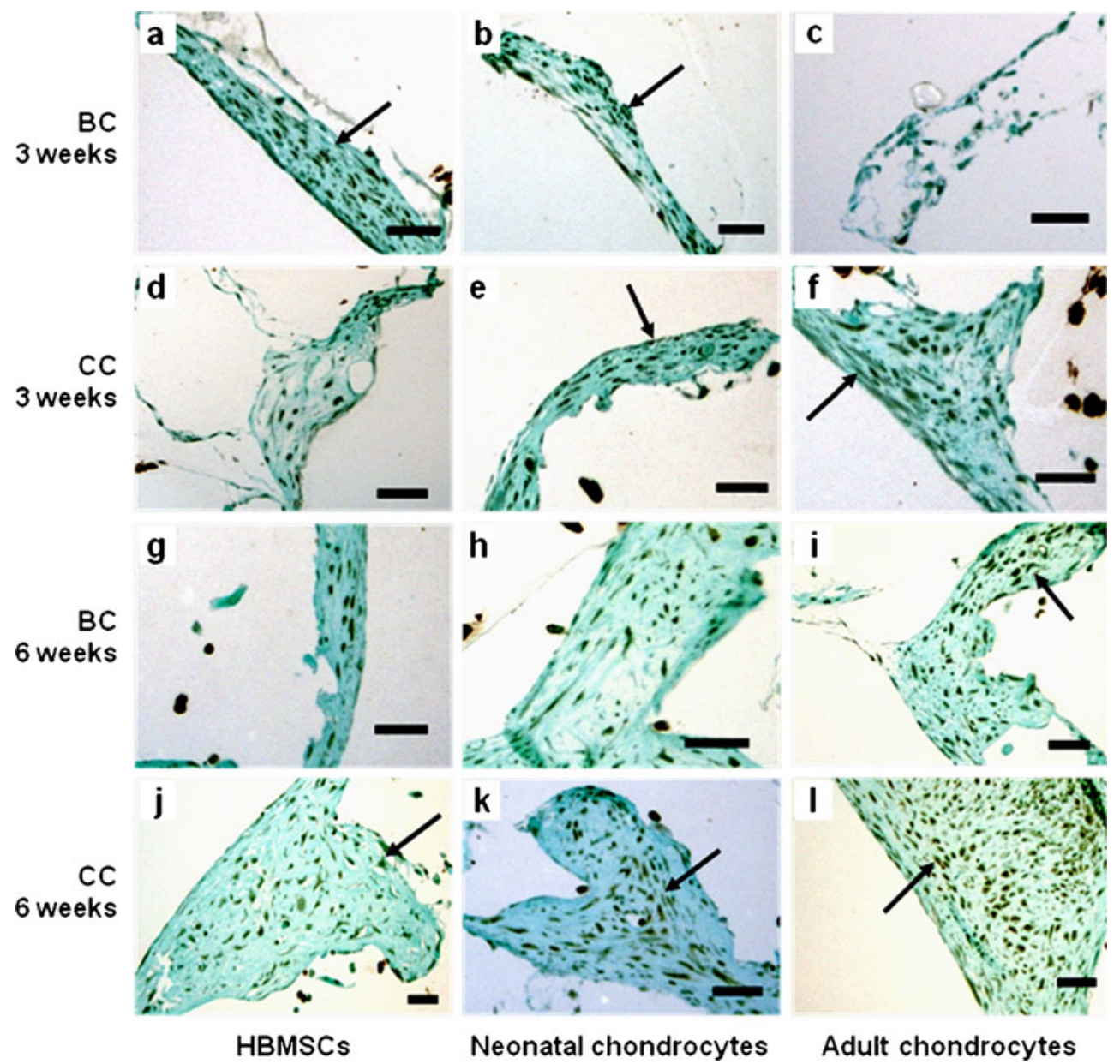

vivo (Fig. 6). Qualitatively, for each cell type, more Sox9positive cells appeared to be present in constructs precultured statically in chondrogenic medium than in those pre-cultured in basal medium. Fewer Sox9-positive cells were seen in the chondro-induced constructs for all cell types after 6 weeks in vivo compared with chondroinduced constructs cultured for 3 weeks in vivo. Strong immuno-staining for aggrecan was evident in all of the in vivo constructs with the highest staining intensities being observed for chondro-induced neonatal and adult chondrocyte constructs implanted in vivo for 6 weeks (Fig. 7).

\section{Discussion}

Successful integration of engineered neocartilage with host cartilage is the ultimate goal for cartilage repair. The hypothesis behind functional cartilage tissue engineering is that successful articular cartilage repair/regeneration will involve the ex vivo synthesis of cartilaginous tissue (LeBaron and Athanasiou 2000a). Differences in methodologies used by researchers to investigate cartilage repair have led to conflicting results. No agreed consensus has been reached concerning the ideal scaffold/cell source/regulatory factors (mechanical stimuli and growth factors) best suited for cartilage regeneration (Caplan and Dennis 2006; LeBaron and Athanasiou 2000b) and the specific signalling pathways that induce chondrogenesis remain generally unknown (Kolf et al. 2007).

The success of any cell-based therapy depends upon the selection of an appropriate cell source. Chondrocytes are an obvious choice for de novo engineering of articular cartilage and are used routinely in the clinic for ACI. The main drawback to this approach lies in the need to produce a homogeneous ECM that can theoretically be induced via the application of appropriate biochemical and biomechanical signals (Klein et al. 2009). In order to obtain a functionally relevant tissue-engineered construct, we need to understand tissue histogenesis occurring in vivo. In our previous study, biochemical assays and gene expression analysis of the cells in 2D culture were carried out under conditions mimicking current cell processing methodologies for ACI therapies in the clinic (Saha et al. 2010). In the present study, we have compared the chondrogenic potential of three human cell types, namely HBMSCs, neonatal articular chondrocytes and adult chondrocytes, in 3D constructs in vitro and in vivo. Our primary goal has been to engineer tissues with histological structures resembling those seen in 
Fig. 4 Aggrecan

immunohistochemical staining of in vitro statically cultured constructs. Aggrecan immunohistochemical staining of constructs following basal culture for 3 weeks $(\mathbf{a}-\mathbf{c})$ and 6 weeks (g-i) compared with that of chondro-inductive culture for 3 weeks (d-f) and 6 weeks $(\mathbf{j}-\mathbf{l})$. All sample constructs stained positively for agrrecan (arrows, brown) with qualitatively the highest staining intensity being observed in chondro-induced adult chondrocyte samples cultured for 6 weeks ( $B C$ basal culture, $C C$ chondrogenic culture, HBMSCs human bone marrow stromal cells). Bars $1 \mathrm{~mm}$

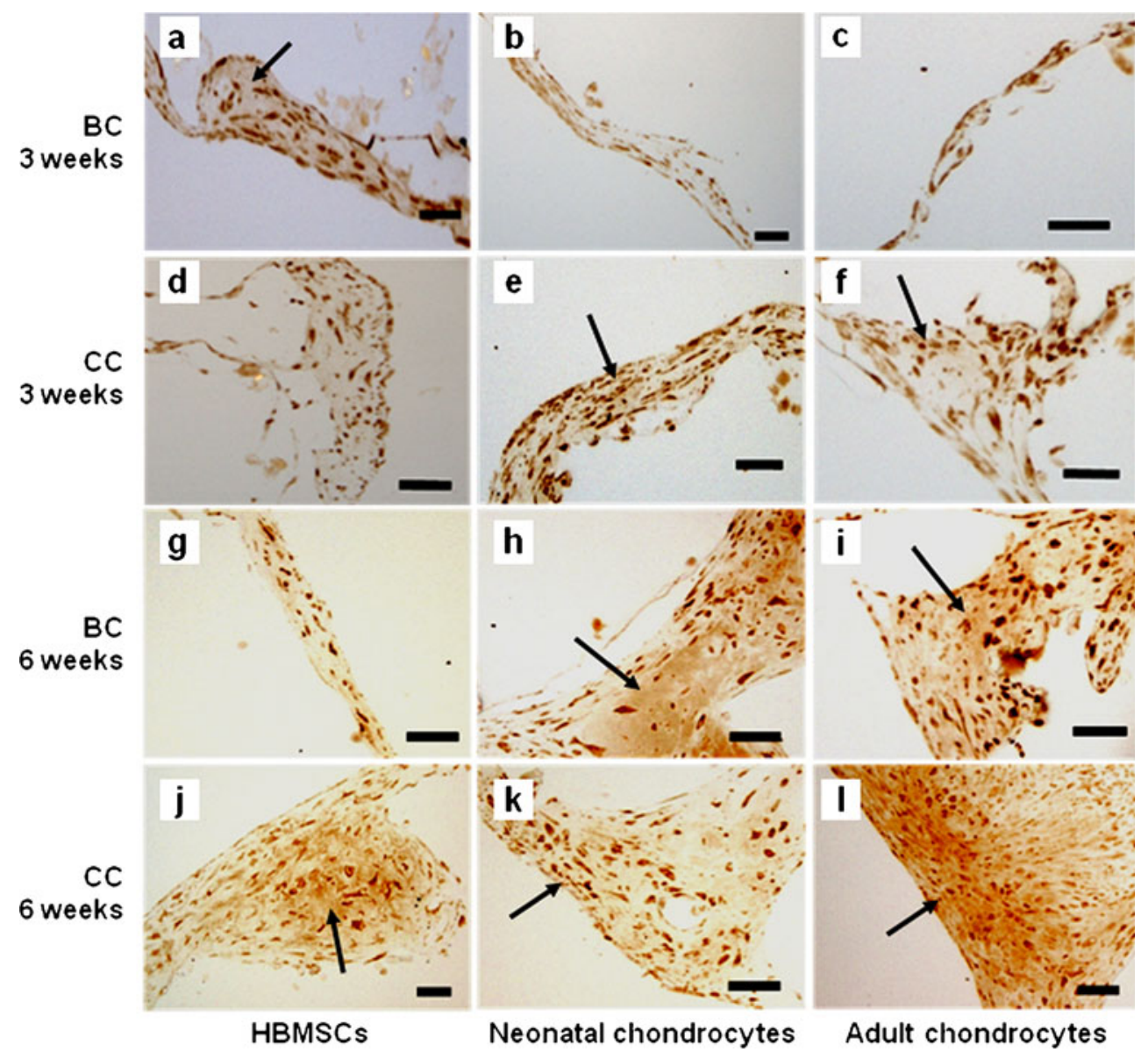

native cartilage, given the apparent importance of morphologically distinct zones in the functioning of healthy articular cartilage (Klein et al. 2009). Ultimately, this work should help to determine the optimum cell source and pre-treatment conditions for ex vivo cartilage generation.

We are aware that the use of neonatal articular chondrocytes as a cell source for cartilage tissue engineering has potential ethical issues. We are not proposing their use as an alternative cell source but have included them in this study because little is known about the behaviour of neonatal articular chondrocytes in culture. Furthermore, we feel that studying these cells alongside mature cartilage cells and stromal cells will help improve our understanding of the biology of chondrocytes and illustrate key differences in the factors that are involved in the differentiation/maintenance of a chondrogenic cell type. In our previous study, for example, we showed differences in temporal gene expression between neonatal articular chondrocytes and the mature cells. In experiments that mimicked current cell processing methodologies in the clinic, our previous work comparing neonatal articular chondrocytes and the mature cell types indicated that signalling events occurred during the first few days of chondrogenic culture prior to the deposition and organisation of a hyaline cartilage ECM. We also showed that the chondrogenic phenotype, which is a balance between proteoglycan content and collagen integrity, was regulated in a sequential/cyclic manner (Saha et al. 2010).

In order to induce chondrogenesis in vitro, we used serum-free $\alpha$-MEM chondrogenic medium containing $10 \mathrm{ng} / \mathrm{ml}$ TGF- $\beta 3$ based upon its known chondroinductive properties (Alhadlaq et al. 2004; Darling and Athanasiou 2003; Pittenger et al. 1999; Tare et al. 2005). All three cell types were seeded onto the cartilage phase of TruFit CB Plug scaffolds of $3 \mathrm{~mm}$ in diameter. Unlike most synthetic scaffolds, TruFit CB Plug scaffolds can support cell attachment and growth without surface modification and promote the repair of osteochondral defects in vivo (Agrawal and Stinson 2007; Williams and Gamradt 2008), including the successful repair of an articular cartilage defect in the human femoral condyle (Carmont et al. 2009).

Static seeding of cells onto the scaffold can result in a clustering of cells at the periphery with an extremely low cell density at the centre (Vunjak-Novakovic et al. 1998; Wendt et al. 2003). A standard dynamic seeding apparatus (17 rpm) designed and manufactured in-house was therefore employed to seed the cells onto the TruFit CB Plug scaffolds and the results confirmed uniform cell viability and cell density throughout the scaffolds for all three cell types used. Following dynamic seeding, the constructs 
Fig. 5 Alcian Blue/Sirius Red staining of cell-scaffold constructs in vivo. After 1 week in vitro culture in basal $(\mathbf{a}-\mathbf{c}, \mathbf{g}-\mathbf{i})$ and chondro-inductive medium $(\mathbf{d}-\mathbf{f}$, $\mathbf{j}-\mathbf{I}$ ), the cells and scaffolds were sealed in diffusion chambers that were implanted intra-peritoneally in nude mice for $3(\mathbf{a}-\mathbf{f})$ or 6 weeks (g-l). Sirius Red staining (arrowheads, red) indicates collagenous matrix formation. Alcian Blue staining (arrows, blue) indicates the presence of muccopolysaccharides in the matrix. After 3 weeks of in vivo implantation, the basal group shows more fibrocartilage-like tissue formation than samples precultured in chondro-inductive medium. At 6 weeks,

fibrocartilage-like tissue formation is observed in both HBMSCs and neonatal chondrocyte constructs pre-incubated in chondroinductive medium. In contrast, adult chondrocytes of the same culture group seem to retain their cartilage-like tissue structure $(B C$ basal culture, $C C$ chondrogenic culture, HBMSCs human bone marrow stromal cells). Bars $1 \mathrm{~mm}$
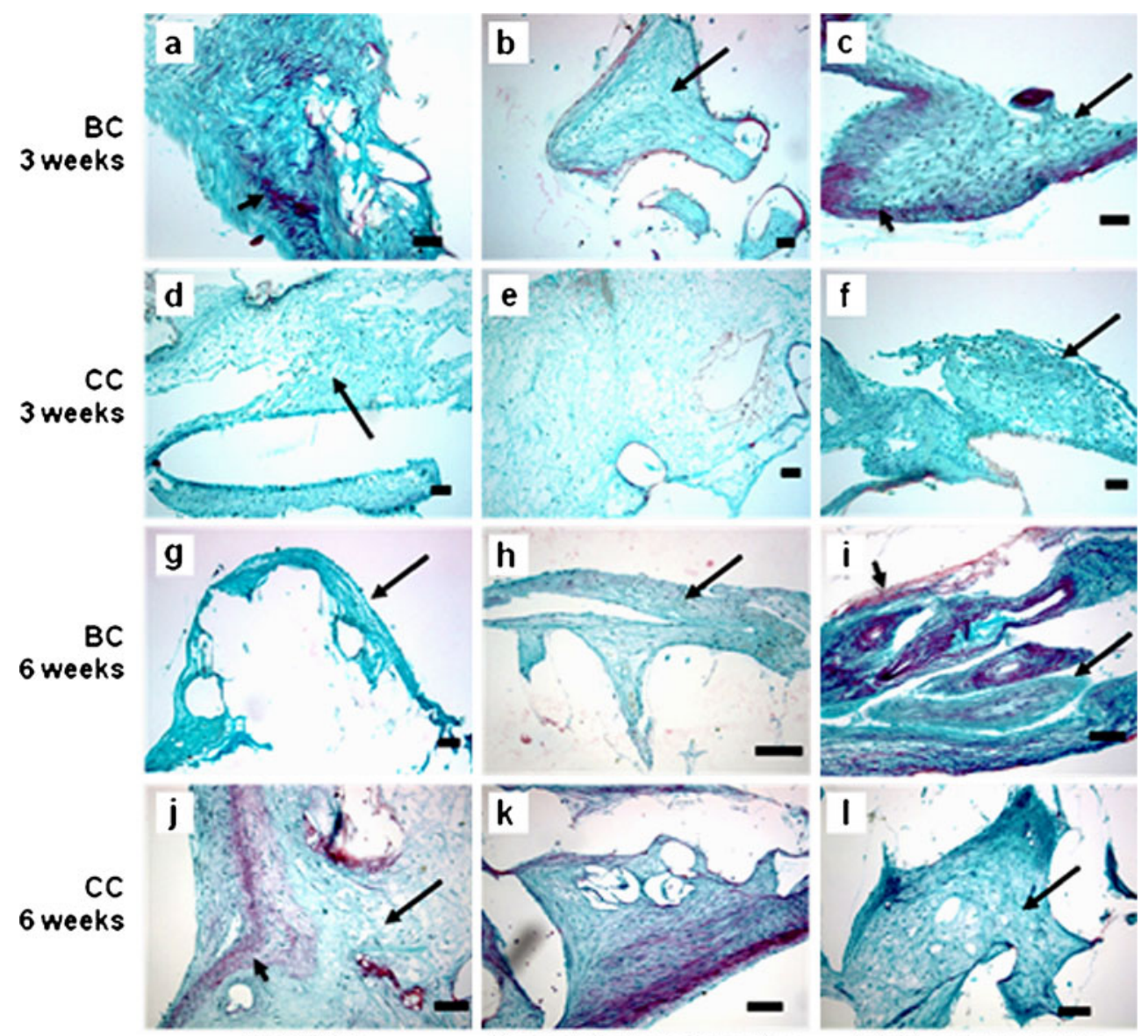

HBMSCs
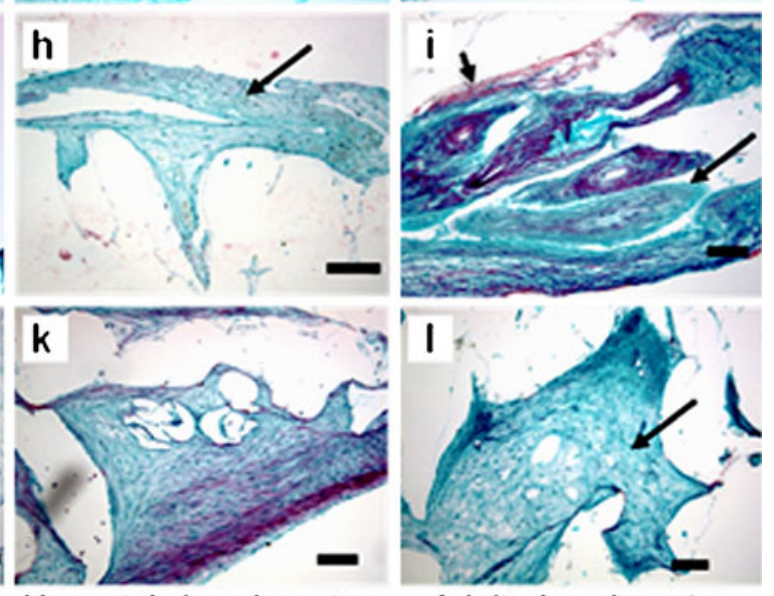

Neonatal chondrocytes

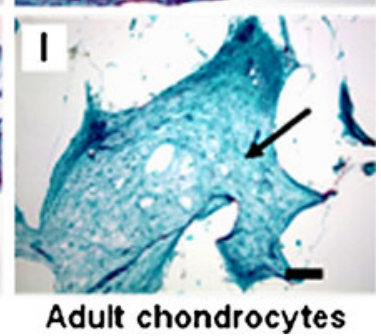

were cultured statically to encourage compressive cell adhesion (CCA).

After 3 weeks of in vitro culture in chondro-induced medium, individual cells embedded in lacunae arranged parallel to the periphery of the scaffolds were observed in all of the constructs further supporting a cartilage-like phenotype. After 6 weeks in vitro, 3D chondro-induced constructs for all three cell types visually appeared to be more cellular compared to their 3-week counterparts. Intense Alcian Blue/Sirius Red staining and pronounced zonal organisation similar to that seen histologically for native articular cartilage (cells appeared flattened and parallel to the surface, with larger rounder cells in the middle-to-base area being aligned perpendicular to the surface) were observed in constructs for all three cell types in chondrogenic medium without any exogenous stimuli or perfusion/diffusion of nutrients. Our results contradict those reported by Seda Tigli and colleagues (2009) who detected faint positive Safranin-O staining for all chondrocyte and MSC constructs over 4 weeks of static chondrogenic culture on chitosan and silk scaffolds, indicative of incomplete chondrogenesis. In the current study, positive Alcian Blue staining characteristic of glycosaminoglycans was seen for all our cell constructs as early as 3 weeks in static chondrogenic culture, indicating that a combination of any of the three cell types with TGF- $\beta 3$ and the PLGA TruFit CB Plug scaffold would be suitable for the induction/short-term maintenance of chondrogenesis. The most interesting observation was that, of all the three cell types studied in vitro, neonatal articular chondrocytes appeared to have formed the thinnest fibrous capsule after 6 weeks of chondrogenic culture compared with the mature cell types. However, the highest staining intensity for Sox9 and aggrecan was observed in the constructs containing chondro-induced adult chondrocytes at 6 weeks.

Most in vivo models used to study chondrogenesis are implant models with the main drawback being apoptosis of almost $85 \%$ of the implanted cells over a 4 -week period (Mierisch et al. 2003; Ostrander et al. 2001). The constructs need first to undergo a period of CCA before in vivo implantation, although highly mature constructs might fail to integrate with the native tissue (Obradovic et al. 2001) and a determination of the extent of in vitro maturation before the 3D construct is placed in vivo is important. In this study, after dynamic seeding onto the scaffold, the 3D constructs were allowed to undergo a week of CCA in static culture in either basal or chondro-induced medium before implantation within diffusion chambers intra-peritoneally in 
Fig. 6 Sox9 immunostaining of cell-scaffod constructs in vivo. Positive staining for Sox 9 (arrows, brown) was seen in constructs after in vivo implantation intra-peritoneally in nude mice for $3(\mathbf{a}-\mathbf{f})$ or 6 weeks $(\mathrm{g}-\mathbf{l})$. Constructs precultured in chondrogenic media stained more intensely for Sox 9 compared with constructs preincubated in basal media. In vivo constructs were qualitatively observed to stain less intensely for Sox9-positive cells compared with the staining observed for constructs cultured in vitro $(B C$ basal culture, $C C$ chondrogenic culture, HBMSCS human bone marrow stromal cells). Bars $1 \mathrm{~mm}$
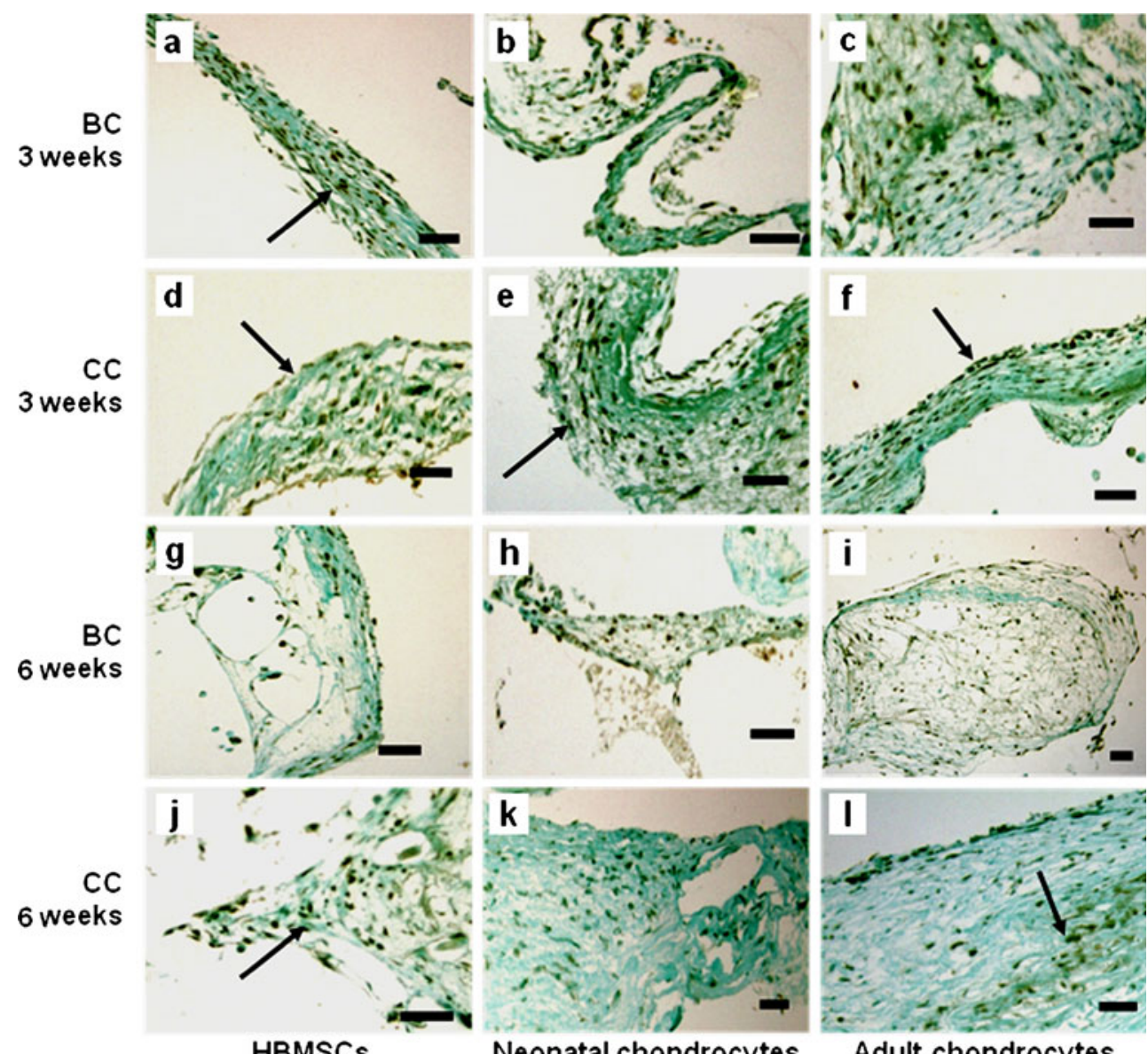

Neonatal chondrocytes

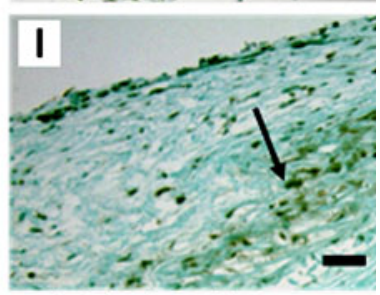

Adult chondrocytes
$\mathrm{Nu} / \mathrm{Nu}$ mice. This time period was based on results from real-time polymerase chain reaction analysis (Saha et al. 2010), which had previously indicated that signalling events occur during the first few days of chondrogenic culture prior to the deposition and organisation of an ECM of hyalinelike cartilage.

The diffusion chamber model provides an enclosed space within the host animal for studies of cellular proliferation/ differentiation without host versus donor tissue rejection (Partridge et al. 2002; Yang et al. 2004). This model approaches an in vivo bioreactor, since the chambers allow the diffusion of nutrients within the peritoneal space similar to articular cartilage in a joint, together with possible (albeit low level) biomechanical loading. In this study, 3D construct samples of all three cell types that were pre-incubated in basal medium formed comparable fibrocartilage-like tissue within 3 weeks of in vivo implantation. After 6 weeks, the adult chondrocyte construct group showed the formation of highly organised fibrocartilage structures. Interestingly, the neo-tissue generated by HBMSCs and neonatal articular chondrocytes under similar conditions lacked any obvious structural organisation and the disorganised tissue was limited. However, pre-incubation in chondrogenic medium was seen to improve the cartilage-like characteristics of the neotissue generated by all three cell types, with no fibrous tissue formation discernable in any of the constructs at 3 weeks. Preincubation in chondrogenic medium for 1 week might therefore help maintain cell signalling pathways post-implantation. Fibrocartilage-like tissue formation was, however, observed after 6 weeks in vivo for both chondro-induced HBMSCs and neonatal chondrocytes. In contrast, adult chondrocyte constructs lacked evidence of any significant fibrous tissue formation and the formed tissue tended to be more compact and had the smallest fibrous capsule (as shown by Sirius Red staining).

The importance of stem cell condensation and homing is now appreciated, making it imperative to be able to recapitulate fully natal and postnatal development for a successful tissue-engineering approach. In vitro chondrogenic induction has been documented to improve the quality of cartilage genesis in vivo (Liu et al. 2007). A 7-day pre-incubation in chondro-induced media has been observed to be sufficient to sustain the chondrogenic phenotype for long-term culture in adult chondrocytes. Perhaps prolonging the preincubation period in vitro to $10-14$ days before in vivo implantation in the case of HBMSCs and neonatal articular chondrocytes would yield a more hyaline-like tissue, even after a long-term culture period.

We have built extensively on our previous research of comparing and contrasting the chondrogenic potential of 
Fig. 7 Aggrecan

immunostaining of in vivo diffusion-chamber-cultured constructs. Positive staining for aggrecan (arrows, brown) was observed in all samples with varying intensities after in vivo implantation intra-peritoneally in nude mice for $3(\mathbf{a}-\mathbf{f})$ or 6 weeks $(\mathrm{g}-\mathbf{l})$. Constructs precultured in chondrogenic media stained more intensely for aggrecan compared with constructs pre-incubated in basal media. Similarly high staining intensities were observed in chondro-induced neonatal and adult chondrocyte constructs implanted in vivo for 6 weeks ( $B C$ basal culture, $C C$ chondrogenic culture, $H B M S C s$ human bone marrow stromal cells). Bars $1 \mathrm{~mm}$

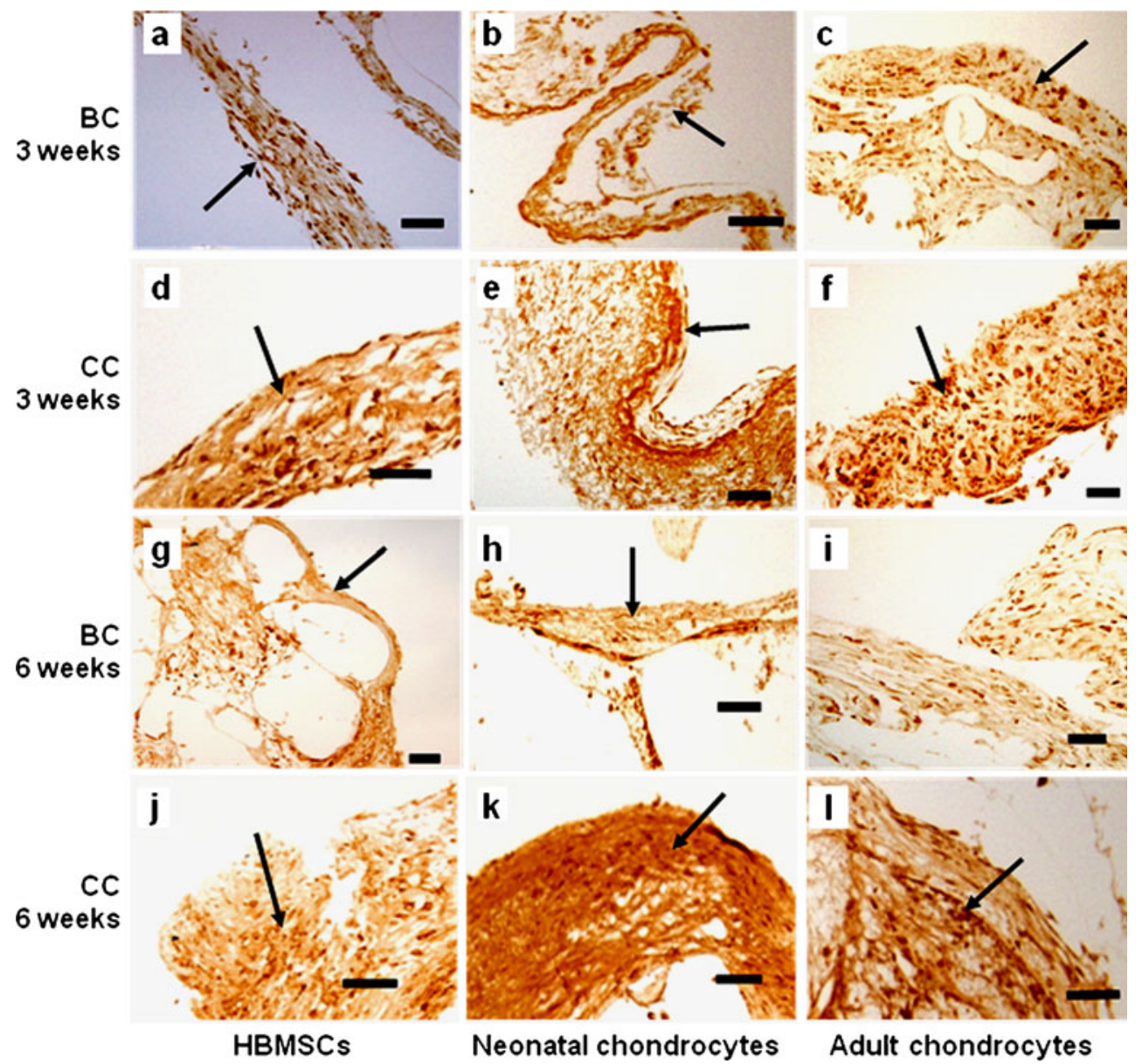

HBMSCs, neonatal articular chondrocytes and adult chondrocytes for indications of optimal chondrogenic potential (Table 1). We have previously documented the three cell types as having different doubling times with the immature cell type (neonatal articular chondrocytes) being the most proliferative of the three cell types and
HBMSCs having the longest doubling time. In order to be in tune with current cell processing methodologies in the clinic, a cell type with a short doubling time is preferred in order to prevent de-differentiation during monolayer expansion (Saha et al. 2010). High alkaline-phosphatase-specific activity (ALPSA) levels in chondrocytes indicate a shift from
Table 1 Comparing and contrasting chondrogenic potential across three human cell types. A rapid visual summary of the observations for a number of specific parameters indicating optimal chondrogenic potential, which is scored qualitatively: a score of,+++ and +++ indicates least, moderate and most ideal cell type, respectively, for the particular parameters being analysed (HBMSCs human bone marrow stromal cells, ALPSA alkaline-phosphatase-specific activity, $q P C R$ quantitative polymerase chain reaction, $3 D$ three-dimensional)
Parameters (reference)

HBMSCs Neonatal articular chondrocytes

Doubling time (Saha et al. 2010)

ALPSA (Saha et al. 2010)

Aggrecan; qPCR and immunohistochmistry (Saha et al. 2010)

Alcian Blue/Sirius Red staining of 3D constructs cultured in chondrogenic media in vitro

Alcian Blue/Sirius Red staining of 3D constructs pre-incubated in basal media and cultured in vivo

Effect of iron oxide incorporation on chondrogenic potential after long-term culture (Saha et al. 2012)

$\begin{array}{ll}+++ & +++ \\ + & +++ \\ +++ & ++ \\ + & ++ \\ +++ & ++ \\ + & + \\ - & + \\ + & +++\end{array}$


the proliferative/pre-hypertrophic phase to a hypertrophic differentiation state. Under ordinary basal culture, HBMSCs (default osteogenic potential) exhibit high ALPSA levels, whereas adult chondrocytes have the lowest ALPSA levels. For the purpose of cartilage cell therapy, a cell type with a low default ALPSA is preferred.

Human neonatal cartilage, unlike mature cartilage, is known to contain two types of chondrocytes (Hwang 1978). A lack of understanding exists with respect to the purpose of the two types of chondrocytes in immature cartilage but we have shown there to be considerable differences in chondrogenic gene regulation mechanisms between immature and mature human chondrocytes (Saha et al. 2010, 2012). Neonatal articular chondrocytes cultured in chondrogenic medium have been seen to have the highest level of collagen type II gene expression (a key chondrogenic marker) compared with the other two cell types. This difference in their gene expression might be related to the differences observed at a histological level as, in a 3D construct in vitro, these cells reveal the thinnest fibrous capsule (indicative of a more hyalinelike tissue formation) of the three cell types.

Before in vivo implantation, the samples were allowed 1 week for CCA, with one group additionally being provided with chondro-inductive cues. After in vivo implantation, only the mature chondrocyte constructs formed a cartilagelike tissue with the thinnest fibrous capsule. In the absence of chondro-inductive cues, only the adult chondrocyte group was capable of forming a tissue, although it was fibrous in nature. This in vivo outcome is most likely to have occurred because differentiated mature chondrocytes are able to maintain their chondrogenic/pre-hypertrophic phenotype with chondro-inductive cues provided by TGF- $\beta 3$ in the culture medium. We have previously shown that the addition of TGF- $\beta 3$ in our chondrogenic culture medium decreases cartilage catabolic effects and helps maintain a prehypertrophic chondrogenic phenotype while inducing chondrogenesis in HBMSCs (Saha et al. 2010). Evidence has been presented that aggrecan is co-expressed with Sox 9 across all three cell types (Saha et al. 2010; Sengers et al. 2007; Shukunami et al. 1997; Tare et al. 2005). In this study, we have confirmed these data via immunohistochemistry in $3 \mathrm{D}$ cultures, both in vitro and in vivo. This is a direct consequence of Sox 9 promoting the gene expression of cartilage-type ECM by binding to the promoter elements of aggrecan (Saha et al. 2010).

The TGF- $\beta 3$ in the culture medium only helps to differentiate the de-differentiated immature chondrocytes and undifferentiated HBMSCs. It is unable to maintain the chondrogenic phenotype of these two cell populations during long-term culture in vivo. In a controlled in vitro environment, e.g., after 6 weeks culture in chondrogenic medium, neonatal chondrocyte constructs successfully form structures that mimic native articular cartilage, with minimal fibrous tissue formation, to a greater extent than is seen for the other cell types. However, under in vivo conditions, even chondro-induced neonatal articular chondrocytes fail to retain a hyaline-like structure.

In the field of cartilage tissue engineering, confusion still surrounds the difference between chondrogenic induction and the maintenance of the chondrocyte phenotype. Differences in the ability of TGF- $\beta 3$ to maintain a chondrogenic phenotype in HBMSCs and neonatal articular chondrocytes can be attributed to a difference in the pattern of the temporal gene expression of key chondrogenic markers when the cells are cultured with this growth factor (Saha et al. 2010) or when they are cultured with medium containing metal ions (Saha et al. 2012). $\operatorname{Smad} 2 / 3$ has been reported to bind to $\operatorname{Sox} 9$ in a manner dependent upon TGF- $\beta$ to form transcriptional complexes that enhance chondrogenesis (Furumatsu et al. 2005). The threshold level of TGF- $\beta$ that impacts on relevant chondrogenic gene markers is not known and, possibly, higher concentrations of the growth factor help maintain the chondrogenic phenotype of neonatal articular chondrocytes and HBMSCs for a longer duration.

Our research highlights the need for a better understanding between chondro-inductive factors and those factors that support the maintenance of a chondrogenic phenotype. Furthermore, our results emphasise the importance of sustained growth factor incorporation for the maintenance of a chondrocyte-like phenotype in immature chondrocytes or undifferentiated HBMSCs.

In conclusion, this study has provided evidence that (1) the chondrogenic medium used enhances cartilage matrix formation in vitro and in vivo but, although supporting the differentiation of HBMSCs, is unable to maintain their chondrogenic phenotype in long-term cultures; (2) the same inductive medium is capable of maintaining the chondrogenic phenotype of adult chondrocytes in long-term cultures but not of neonatal chondrocytes; (3) immature (neonatal) chondrocytes appear to be highly dependent on chondro-inductive growth factors for the formation and maintenance of the cartilage phenotype, both in short-term and in long-term cultures. Thus, under chondrogenic culture conditions, adult chondrocytes appear to be a more promising cell source than HBMSCs for use in articular cartilage tissue engineering.

Open Access This article is distributed under the terms of the Creative Commons Attribution License which permits any use, distribution, and reproduction in any medium, provided the original author(s) and the source are credited.

\section{References}

Agrawal V, Stinson M (2007) Arthroscopic grafting of greater tuberosity cyst and rotator cuff repair. Arthroscopy 23:904.e901-904.e903 
Alhadlaq A, Elisseeff JH, Hong L, Williams CG, Caplan AI, Sharma B, Kopher RA, Tomkoria S, Lennon DP, Lopez A, Mao JJ (2004) Adult stem cell driven genesis of human-shaped articular condyle. Ann Biomed Eng 32:911-923

Baksh D, Yao R, Tuan RS (2007) Comparision of proliferative and multilineage differentiation potential of human mesenchymal stem cells derived from umbilical cord and bone marrow cells. Stem Cells 25:1384-1392

Brittberg M, Lindahl A, Nilsson A, Ohlsson C, Isaksson O, Peterson L (1994) Treatment of deep cartilage defects in the knee with autologous chondrocyte transplantation. N Engl J Med 331:889-895

Caplan AI, Dennis JE (2006) Mesenchymal stem cells as trophic mediators. J Cell Biochem 98:1076-1084

Carmont MR, Carey-Smith R, Saithna A, Dhillon M, Thompson P, Spalding T (2009) Delayed incorporation of a trufit plug: perseverance is recommended. Arthroscopy 25:810-814

Chen FH, Tuan RS (2008) Mesenchymal stem cells in arthritic diseases. Arthritis Res Ther 10:223

Chen J, Wang C, Lü S, Wu J, Guo X, Duan C, Dong L, Song Y, Zhang J, Jing D, Wu L, Ding J, Li D (2005) In vivo chondrogenesis of adult bone-marrow-derived autologous mesenchymal stem cells. Cell Tissue Res 319:429-438

Clar C, Cummins E, McIntyre L, Thomas S, Lamb J, Bain L, Jobanputra P, Waugh N (2005) Clinical and cost-effectiveness of autologous chondrocyte implantation for cartilage defects in knee joints: systematic review and economic evaluation. Health Technol Assess 9:1-82

Darling EM, Athanasiou KA (2003) Biomechanical strategies for articular cartilage regeneration. Ann Biomed Eng 31:1114-1124

Dominici M, Le Blanc K, Mueller I, Slaper-Cortenbach I, Marini F, Krause D, Deans R, Keating A, Prockop D, Horwitz E (2006) Minimal criteria for defining multipotent mesenchymal stromal cells. The International Society for Cellular Therapy position statement. Cytotherapy 8:315-317

Emans PJ, Surtel DAM, Frings EJJ, Bulstra SK, Kuijer R (2005) In vivo generation of cartilage from periosteum. Tissue Eng 11:369-377

Estes BT, Wu AW, Guilak F (2006) Potent induction of chondrocytic differentiation of human adipose-derived adult stem cells by bone morphogenetic protein 6 . Arthritis Rheum 54:1222-1232

Furumatsu T, Tsuda M, Taniguchi N, Tajima Y, Asahara H (2005) Smad3 induces chondrogenesis through the activation of SOX9 via CREB-binding protein/p300 recruitment. J Biol Chem 280:8343-8350

Grad I, Hibaoui Y, Jaconi M, Chicha L, Bergstrom-Tengzelius R, Sailani MR, Pelte MF, Dahoun S, Mitsiadis TA, Tohonen V, Bouillaguet S, Antonarakis SE, Kere J, Zucchelli M, Hovatta O, Feki A (2011) NANOG priming before full reprogramming may generate germ cell tumours. Eur Cell Mater 22:258-274

Gu YD, Cheng DS, Zhang GM, Chen XM, Xu JG, Yang XB (1997) Long-term results of toe transfer: retrospective analysis. J Reconstr Microsurg 13:405-408

Horwitz EM, Gordon PL, Koo WKK, Marx JC, Neel MD, McNall RY, Muul L, Hofmann T (2002) Isolated allogeneic bone marrowderived mesenchymal cells engraft and stimulate growth in children with osteogenesis imperfecta: implications for cell therapy of bone. Proc Natl Acad Sci 99:8932-8937

Hwang WS (1978) Ultrastructure of human foetal and neonatal hyaline cartilage. J Pathol 126:209-214

Johnstone B, Hering TM, Caplan AI, Goldberg VM, Yoo JU (1998) In vitro chondrogenesis of bone marrow-derived mesenchymal progenitor cells. Exp Cell Res 238:265-272

Klein T, Malda J, Sah R, Hutmacher D (2009) Tissue engineering of articular cartilage with biomimetic zones. Tissue Eng Part B Rev $15: 143-157$

Kolf CM, Cho E, Tuan RS (2007) Mesenchymal stromal cells. Biology of adult mesenchymal stem cells: regulation of niche, self-renewal and differentiation. Arthritis Res Ther 9:204
LeBaron RG, Athanasiou KA (2000a) Ex vivo synthesis of articular cartilage. Biomaterials 21:2575-2587

LeBaron RG, Athanasiou KA (2000b) Extracellular matrix cell adhesion peptides: functional applications in orthopedic materials. Tissue Eng 6:85-103

Lin Y, Luo E, Chen X, Liu L, Qiao J, Yan Z, Li Z, Tang W, Zheng X, Tian W (2005) Molecular and cellular characterization during chondrogenic differentiation of adipose tissue-derived stromal cells in vitro and cartilage formation in vivo. J Cell Mol Med 9:929-939

Liu W, Zhang W, Cao Y (2007) Bone and cartilage reconstruction. In: Lanzer R, Langer R, Vacanti J (eds) Principles of tissue engineering. Elsevier/Academic Press, Amsterdam/San Diego, pp 861-876

Mackay A, Beck S, Murphy J, Barry F, Chichester C, Pittenger M (1998) Chondrogenic differentiation of cultured human mesenchymal stem cells from marrow. Tissue Eng 4:415-428

Mierisch CM, Wilson HA, Turner MA, Milbrandt TA, Berthoux L, Hammarskjold M-L, Rekosh D, Balian G, Diduch DR (2003) Chondrocyte transplantation into articular cartilage defects with use of calcium alginate: the fate of the cells. J Bone Joint Surg Am 85:1757-1767

Obradovic B, Martin I, Padera RF, Treppo S, Freed LE, VunjakNavakovic G (2001) Integration of engineered cartilage. J Orthop Res 19:1089-1097

Ostrander RV, Goomer RS, Tontz WL, Khatod M, Harwood FL, Maris TM, Amiel D (2001) Donor cell fate in tissue engineering for articular cartilage repair. Clin Orthop Relat Res 389:228-237

Partridge K, Yang X, Clarke NMP, Okubo Y, Bessho K, Sebald W, Howdle SM, Shakesheff KM, Oreffo ROC (2002) Adenoviral BMP-2 gene transfer in mesenchymal stem cells: in vitro and in vivo bone formation on biodegradable polymer scaffolds. Biochem Biophys Res Commun 292:144-152

Penick K, Solchaga L, Welter J (2005) High-throughput aggregate culture system to assess the chondrogenic potential of mesenchymal stem cells. Biotechniques 39:687-691

Pittenger MF, Mackay AM, Beck SC, Jaiswal RK, Douglas R, Mosca JD, Moorman MA, Simonetti DW, Craig S, Marshak DR (1999) Multilineage potential of adult human mesenchymal stem cells. Science 284:143-147

Ponticiello MS, Schinagl RM, Kadiyala S, Barry FP (2000) Gelatinbased resorbable sponge as a carrier matrix for human mesenchymal stem cells in cartilage regeneration therapy. J Biomed Mater Res 52:246-255

Redman SN, Oldfield SF, Archer CW (2005) Current strategies for articular cartilage repair. Eur Cell Mater 9:23-32

Ringe J, Sittinger M (2009) Tissue engineering in the rheumatic diseases. Arthritis Res Ther 11:211

Rodriguez-Merchan EC (2012) The treatment of cartilage defects in the knee joint: microfracture, mosaicplasty, and autologous chondrocyte implantation. Am J Orthop (Belle Mead NJ) 41:236-239

Saha S, Kirkham J, Wood D, Curran S, Yang X (2010) Comparative study of the chondrogenic potential of human bone marrow stromal cells, neonatal chondrocytes and adult chondrocytes. Biochem Biophys Res Commun 401:333-338

Saha S, Kirkham J, Wood D, Curran S, Yang XB (2011) Adult stem cells for articular cartilage tissue engineering. In: Li S, L'Heureux, Elisseeff J(ed) Stem cell and tissue engineering. World Scientific, Singapore, pp 211-230

Saha S, Yang XB, Tanner S, Curran S, Wood D, Kirkham J (2012) The effects of iron oxide incorporation on the chondrogenic potential of three human cell types. J Tissue Eng Regen Med (in press)

Seda Tigli R, Ghosh S, Laha MM, Shevde NK, Daheron L, Gimble J, Gumusderelioglu M, Kaplan DL (2009) Comparative chondrogenesis of human cell sources in 3D scaffolds. J Tissue Eng Regen Med $3: 348-360$ 
Sengers BG, Please CP, Oreffo RO (2007) Experimental characterization and computational modelling of two-dimensional cell spreading for skeletal regeneration. J R Soc Interface 4:1107-1117

Shintani N, Hunziker EB (2007) Chondrogenic differentiation of bovine synovium: bone morphogenetic proteins 2 and 7 and transforming growth factor betal induce the formation of different types of cartilaginous tissue. Arthritis Rheum 56:1869-1879

Shukunami C, Ishizeki K, Atsumi T, Ohta Y, Suzuki F, Hiraki Y (1997) Cellular hypertrophy and calcification of embryonal carcinomaderived chondrogenic cell line ATDC5 in vitro. J Bone Miner Res 12:1174-1188

Tare RS, Howard D, Pound JC, Roach HI, Oreffo ROC (2005) Tissue engineering strategies for cartilage generation-micromass and three dimensional cultures using human chondrocytes and a continuous cell line. Biochem Biophys Res Commun 333:609-621

Tuan RS, Boland G, Tuli R (2003) Adult mesenchymal stem cells and cell-based tissue engineering. Arthritis Res Ther 5:32-45

Tuli R, Li WJ, Tuan RS (2003) Current state of cartilage tissue engineering. Arthritis Res Ther 5:235-238

Vasiliadis H, Wasiak J, Salanti G (2010) Autologous chondrocyte implantation for the treatment of cartilage lesions of the knee: a systematic review of randomized studies. Knee Surg Sports Traumatol Arthrosc 18:1645-1655

Vunjak-Novakovic G, Obradovic B, Martin I, Bursac PM, Langer R, Freed LE (1998) Dynamic cell seeding of polymer scaffolds for cartilage tissue engineering. Biotechnol Prog 14:193-202

Wakitani S, Imoto K, Yamamoto T, Saito M, Murata N, Yoneda M (2002) Human autologous culture expanded bone marrow mesenchymal cell transplantation for repair of cartilage defects in osteoarthritic knees. Osteoarthritis Cartilage 10:199-206

Wayne JS, McDowell CL, Shields KJ, Tuan RS (2005) In vivo response of polylactic acid-alginate scaffolds and bone marrow-derived cells for cartilage tissue engineering. Tissue Eng 11:953-963

Wei Y, Zeng W, Wan R, Wang J, Zhou Q, Qiu S, Singh SR (2012) Chondrogenic differentiation of induced pluripotent stem cells from osteoarthritic chondrocytes in alginate matrix. Eur Cell Mater 23:1-12

Wendt D, Marsano A, Jakob M, Heberer M, Martin I (2003) Oscillating perfusion of cell suspensions through three-dimensional scaffolds enhances cell seeding efficiency and uniformity. Biotechnol Bioeng 84:205-214

Williams R, Gamradt S (2008) Articular cartilage repair using a resorbable matrix scaffold. Instr Course Lect 57:563-671

Yanai T, Ishii T, Chang F, Ochiai N (2005) Repair of large fullthickness articular cartilage defects in the rabbit: the effects of joint distraction and autologous bone marrow derived mesenchymal cell transplantation. J Bone Joint Surg Br 87:721-729

Yang XB, Gu YD (2000) The donor foot in free toe or joint transfers. J Hand Surg Br 25:382-384

Yang X, Whitaker M, Sebald W, Clarke N, Howdle S, Shakesheff K, Oreffo R (2004) Human osteoprogenitor bone formation using encapsulated bone morphogenetic protein 2 in porous polymer scaffolds. Tissue Eng 10:1037-1045

Yang XB, Webb D, Blaker J, Boccaccini AR, Maquet V, Cooper C, Oreffo RO (2006) Evaluation of human bone marrow stromal cell growth on biodegradable polymer/bioglass composites. Biochem Biophys Res Commun 342:1098-1107 